\section{Outcome of management of obstetric genito-urinary fistulae in the general hospital, Ikot Ekpene, Akwa Ibom state, Nigeria}

\author{
Etim I. Ekanem,' Mabel I. Ekott,' \\ John E. Ekabua, 'Thomas U. Agan,' \\ Atta Inyang-Otu ${ }^{2}$ \\ 'Department of Obstetrics and \\ Gynecology, University of Calabar \\ Teaching Hospital, Calabar, Nigeria; \\ 2Department of Surgery General Hospital \\ Ikot Ekpene, Akwa Ibom State, Nigeria
}

\begin{abstract}
Background. Obstetric fistula with urinary incontinence is one of the most distressing maternal morbidities. It is associated with physical and social deprivation such as wife abandonment and violent reactions against the victims, particularly in the developing countries of the world. This study was carried out to assess the demographic and reproductive profiles as well as outcome of management of patients with obstetric genito-urinary fistulae in the General Hospital Ikot Ekpene, Akwa Ibom State, Nigeria.

Design and Methods. A five-year cross sectional observational study of medical records of 37 patients managed in maternity section of General Hospital Ikot Ekpene, Akwa Ibom State, Nigeria was conducted.
\end{abstract}

Results. One in every 122 deliveries during the study period was complicated by urinary fistula. Eleven (29.7\%) were teenagers. Most patients were married (54.1\%), primiparous (59.4\%) from low socioeconomic class (72.9\%) who did not utilize modern obstetric facilities effectively. Many cases were the consequence of prolonged obstructed labour (51.4\%) and majority presented with total incontinence of urine (70.2\%). Eighteen (48.7\%) patients presented within 6 months of delivery. They were mainly vesico-vaginal (34.4\%) or complex (10.8\%) fistulae that were managed conservatively (21.6\%) or with bladder repairs. About a third was referred for further management due to unsatisfactory outcome.

Conclusions. This age-long obstetric morbidity is common among young married women in Ikot Ekpene, Akwa Ibom, mainly due to poor utilization of modern obstetric care facilities. Results of treatment are largely unsatisfactory in a third of these patients; therefore resources should be channeled towards effective and comprehensive preventive programs especially among this vulnerable group of women.

\section{Introduction}

Uro-genital fistula is one of the most serious and distressing maternal morbidities. ${ }^{1,2}$ In developed countries of the world the problem is so rare that most obstetricians may go through their entire career without seeing an obstetric fistula. When it occurs, it is usually a consequence of complex surgical interventions at delivery. ${ }^{3,4}$ It is therefore more likely to be anticipated, easily recognized and promptly treated. The patients do not often suffer long term complications of this problem. ${ }^{5,6}$ In developing countries, however, this condition occurs mostly in young, poor patients who suffer from neglected prolonged obstructed labour with limited access to modern obstetric care. These patients, therefore, present in the hospital for treatment with urinary incontinence sometimes years after the injuries. ${ }^{1,2,7,8,9}$

Most of them are abandoned by relatives, thus becoming victims of social outcast and suffering other violent reactions from a hostile society. They also fail to realize their dreams of becoming mothers as most of their babies are stillborn. ${ }^{7,10}$ These evoke intense physical and psychological depressions.

Before the $17^{\text {th }}$ century, this age-long problem was hopeless, with efforts at treatment mainly directed at procuring receptacle for collection of urine at the vulva and patients neglected to their own plight. $^{3}$ Since the first attempt at repair of vesicovaginal fistula by $\mathrm{H}$. Van Roonhuyse in 1693, great advances and innovations have been introduced by various workers such as George Hayward (1839), Marion Sims (1852), Trendelenburg (1890), Kelly (1893), Ltzko (1942) and Martins to the management of this problem. ${ }^{3,8,11}$ Huge successes have been recorded in the treatment of this condition in recent times, such that most patients are made to regain continence even in most complicated and complex fistulae., ${ }^{4,8,12-15}$ The success of treatment in modern times depends on a number of factors including proper patient selection, experience of the surgical team, dedicated nursing care and proper integrating of the patients to the general society. ${ }^{1,2,15}$ These factors require regionalization of treatment for optimal specialized care and this is not readily obtained in most poor developing countries. Efforts should therefore be directed toward effective, preventive programs targeting the most vulnerable group of women.

This study was carried out to review the demographic and reproductive profiles as well as management of patients with obstetric genito-urinary fistulae in a tertiary institution in a developing country. It is hoped that the outcome of this research will assist in the planning of effective preventive strategies and maximizing care of those who sustained this injuries during childbirth.
Correspondence: Dr. Etim I. Ekanem, Department of Obstetrics and Gynaecology, University of Calabar Teaching Hospital Calabar, Moore Road, Calabar, Cross River, Nigeria.

Tel. +23.480.63921756.

E-mail: ekanmetim@yahoo.com

Key words: obstetrics, morbidity, fistulae, injury.

Received for publication: 15 July 2010

Revision received: 6 December 2010.

Accepted for publication: 13 December 2010.

This work is licensed under a Creative Commons Attribution 3.0 License (by-nc 3.0).

(C) Copyright E.I. Ekanem et al., 2010

Licensee PAGEPress, Italy

Urogynaecologia 2010; 24:e1

doi:10.4081/uij.2010.e1

\section{Design and Methods}

This is a cross sectional observational study of patients with obstetric fistulae in the General Hospital Ikot Ekpene, Akwa Ibom State, Nigeria, over a five-year period ( $1^{\text {st }}$ January 2005 to $31^{\text {st }}$ December 2009) after obtaining appropriate approval from the hospital ethical committee for human research. The hospital is a government secondary health care referral institution in the state, which receives patients from surrounding states and local government area. It has an annual of 2569 gynecological consultations with 4 subspecialties of which uro-gynecology is newly developed for about 2 years. The institution also has annual delivery of 1150 maternities. The state is located in the Niger delta region of Nigeria, with about 2.5 million people, whose main occupations include farming, petty trading, civil service and housewife.

All the patients with a diagnosis of genito-urinary fistulas following delivery in the hospital were included in the study.

Those excluded from the study were:

1. Patients who had fistulae following termination of pregnancy before 28 weeks gestation.

2. Non-pregnant women with fistulae.

3. Pregnant women who had traumatic injuries not related to pregnancy or its management.

4. Patients whose diagnosis was not clear or confirmed by appropriate procedure.

5. Those whose records were not complete for analysis.

The demographic and reproductive data such as age, occupation, marital status, parity and booking characteristics of the patients were obtained by a pre-tested semi-structured questionnaires administered by the authors after informed consent was obtained on admission to ward and $6^{\text {th }}$ week follow-up at the gynecological clinic. The case files of these patients were then retrieved from medical records department for in depth study. Information was also obtained from 
records in labour ward and operation theatre for those who had previously been managed in the hospital. Information abstract included, mode of presentation, type of fistulae and mode of definitive treatment given as well as the outcome and complications were also noted.

The diagnosis and type of fistulae were made following the findings at:

1. Examination under anesthesia and transurethral instillation of diluted methylene blue dye into the urinary bladder.

2. Three swabs test using white cotton wool ball placed in the vaginal fornices, mid vagina and at the introitus respectively with methylene blue dye study.

3. Intravenous urogram or micturating urethrogram.

4. Cystoscopic examination.

5. Surgical evaluation.

For the purpose of this study the following definitions were applied.

Classification, as per the Waaldijk's ranking of 1995: i) complex fistula described patients with multiple urogenital fistulae which do not fit into routine descriptions; ii) combined fistulae are genito-urinary fistulae with associated rectovaginal fistulae with or without fecal incontinence.

Assessment of management outcome: i) satisfactory, meaning the woman regained complete continence; ii) unsatisfactory, meaning the women did not regain complete continence. Patients were allocated to various form of treatment modalities based on type and duration of fistulas and availability of experienced surgeons.

Booking status: i) booked patients were those who had satisfactory antenatal care and skilled attendance in labor during the index pregnancy; ii) unbooked patients were those seen for the first time in labor without prior antenatal care; iii) defaulters were patients who registered but failed to continue with follow-up antenatal care only to be seen in the late active stage of labor; iv) interfered patients were those who had good antenatal care but did not have skilled care in labor.

Social class classifications based on Modified Registrar General's 5-point occupational scale ${ }^{16}$

\begin{tabular}{ll}
\hline Social class & Description \\
\hline I & Professional \\
& (Lawyers, medical doctors) \\
& Business \\
(Large employers) \\
II & Lesser profession \\
& (Teachers) \\
& Trading \\
& (Big traders) \\
III & Skilled non-manual \\
& (Clerical officers) \\
& Skilled manual \\
& (Electricians) \\
IV & Semi-skilled manual \\
& (Farmers, petty traders) \\
V & Unskilled manual \\
& (Laborers) \\
\hline
\end{tabular}

\section{Results}

A total of 4520 deliveries were conducted during the period and 49 genito-urinary fistulae were managed, of which 37 (75.5\%) were due to obstetric related complications. Thus, the incidence of 8.2 in 1000 or 1 in 122 deliveries was obtained.

Table 1 shows the socio-demographic and reproductive characteristics of patients with obstetric fistulae in Ikot Ekpene. Most of them (51.4\%) were between 20 and 30 years of age and $11(29.7 \%)$ were teenagers. Twenty-seven patients $(72.9 \%)$ were from low socioeconomic class (IV and V), while 20 (54.1\%) were married. Twenty-two (59.4\%) were primiparous; fourteen (37.8\%) were unbooked, while $48.6 \%$ attempted delivery outside orthodox medical facilities even though they had good antenatal care.

Table 2 shows predisposing factors and clinical presentation of patients with fistulas. Ninteen (54.4\%) fistulae were related to a complication of prolonged obstructed labour. Some of them (3) followed operative vaginal (8.1\%) and five (13.5\%) followed abdominal deliveries. Majority 26 (70.2\%) presented with total urinary incontinence. Intermittent leakage of urine and copious vaginal discharge were seen in $21.6 \%$ and $24.3 \%$ respectively. Eighteen patients (48.7\%) presented within 3 months of delivery in the hospital and only 7 (18.9\%) were seen after one year of sustaining the injury.

Table 3 shows the types and modes of treatment of fistulae in Ikot Ekpene hospital.

Twelve patients (34.4\%) had vesicovaginal fistulae and were mainly midvaginal (8) and juxtra urethra (3). Others types encountered were uretero-vaginal, combined and complex types in $4(0.8 \%), 8(21.6 \%)$ and $4(10.8 \%)$ patients respectively. Most patients (8) were managed conservatively (21.6\%), 6 (16.2\%) had bladder and vaginal repair while 11 (29.7\%) were referred.

Table 4 shows mode of treatment and outcome. Most of the patients(56.8\%) had satisfactory outcome, but this was mainly from patients with conservative treatment and ureteric surgical interventions. The majority (61.5\%) of those with unsatisfactory results were referred for further treatments.

\section{Discussion}

The incidence of genitourinary fistula of 8.2 per 1000 in this study seems high when compared to findings from developed countries..$^{17}$ It is however in accord with most reports from developing countries of the world, where 65 $83 \%$ of all fistulae are due to obstetric compli-
Table 1. Socio-demographic and reproductive characteristics of patients with fistulae.

\begin{tabular}{lcc} 
& Patients & $\%$ \\
Age in years & & \\
Less than 20 & 11 & $(29.7)$ \\
$20-30$ & 19 & $(51.4)$ \\
$31-40$ & 5 & $(13.5)$ \\
Above 40 & 2 & $(5.4)$ \\
Social class & & \\
I & 2 & $(2.7)$ \\
II & 3 & $(8.1)$ \\
III & 6 & $(16.2)$ \\
IV & 9 & $(24.3)$ \\
V & 17 & $(45.9)$ \\
\hline Marital status & & \\
Married & 20 & $(54.1)$ \\
Unmarried & 13 & $(35.1)$ \\
Others & 4 & $(10.8)$ \\
Parity & & \\
1 & 22 & $(59.4)$ \\
2-4 & 10 & $(27.0)$ \\
5 and more & 5 & $(13.5)$ \\
\hline Booking status & & \\
Booked & 5 & $(13.5)$ \\
Unbooked & 14 & $(37.8)$ \\
Interfered & 10 & $(27.0)$ \\
Defaulters & 8 & $(21.6)$ \\
\hline
\end{tabular}

Table 2. Predisposing factors and mode of clinical presentation of patients with fistula.

\begin{tabular}{lll} 
& Patients & $\%$ \\
Predisposing factors & & \\
Prolonged obstructed labour & 19 & $(54.4)$ \\
Instrumental vaginal deliveries & 3 & $(8.1)$ \\
Operative abdominal delivery & 5 & $(13.5)$ \\
Ruptured uterus & 4 & $(10.8)$ \\
Others & 6 & $(16.2)$ \\
Clinical presentation & & \\
Total incontinence of urine & 26 & $(70.2)$ \\
Intermittent leakage of urine & 8 & $(21.6)$ \\
Copious vaginal discharge & 9 & $(24.3)$ \\
Abdominal pains/swelling & 3 & $(8.1)$ \\
Vulvae dermatitis/vaginal stenosis & 6 & $(16.2)$ \\
Other & 4 & $(10.8)$ \\
\hline
\end{tabular}

Table 3. Types and treatment outcome of urogenital fistula.

\begin{tabular}{|c|c|c|}
\hline & No. & $\%$ \\
\hline \multicolumn{3}{|l|}{ Type of fistulae } \\
\hline Vesico-vaginal & 12 & $(34.4)$ \\
\hline Uretero-vaginal & 4 & $(10.8)$ \\
\hline Urethro-vaginal & 3 & $(8.1)$ \\
\hline Utero-vesical & 2 & $(5.4)$ \\
\hline Combined & 8 & $(21.6)$ \\
\hline Complex & 4 & $(10.8)$ \\
\hline Others & 3 & $(8.1)$ \\
\hline \multicolumn{3}{|l|}{ Mode of treatment } \\
\hline Conservative & 8 & $(21.6)$ \\
\hline Bladder \& vaginal repairs only & 6 & $(16.2)$ \\
\hline $\begin{array}{l}\text { Ureteric excision/repairs/ } \\
\text { implantation }\end{array}$ & 4 & $(10.8)$ \\
\hline Urethroplasty & 3 & $(8.1)$ \\
\hline Other & 5 & (13.5) \\
\hline Referrals & 11 & (29.7) \\
\hline
\end{tabular}


cations. ${ }^{2,79}$ In Katsina state of Nigeria obstetric fistula occurs in 3.5 per 1000 deliveries. ${ }^{18}$

The incidence in this study would probably be higher, considering the fact that there are 150,000 estimated unrepaired cases of fistulae in Northern Nigeria alone. ${ }^{7}$ Also, most patients are reluctant to present themselves for treatment in this specialist centre, due to financial constraints or fear of social embarrassment from unpleasant odor from constant leakage of urine. Moreover, many of these patients seems to prefer a nearby Missionary Hospital where they are treated at a much-reduced cost, coupled with proper rehabilitation programs. However, this study shows that the problems of obstetric fistulae are not uncommon in contemporary obstetric practice in developing countries, where this is a problem for young, poor primiparous patients. . $, 2,7,9$

Similar pattern was also observed in this study. Unlike some of these studies however, our patients were mostly aged 20-30 years (51.4\%) and the majority were married (54.1\%). The age incidence in this study may be due to the fact that women of this age bracket dominate our obstetric population. Socio-cultural practice of early marriage and childbearing seen in other societies are not encouraged in Ikot Ekpene. Indeed, this was of great advantage during the care of these patients as their husbands and other family members supported most of them compared to other reports of total rejection and abandonment in other studies. ${ }^{10,18}$ This boosted their morale and made reintegration and rehabilitation easier and successful in our patients.

The majority of the patients in this study did not utilize the available modern obstetric care facilities effectively. This has also been reported by others from developing countries. ${ }^{7,8,919}$ Of particular note were those who registered for antenatal care but attempted to delivery outside hospital. These patients were kept for days with obstructed labour only to be referred to the hospital after spontaneous delivery of dead babies with subsequent urinary incontinence. Obstetric mortality and morbidities have generally been reported to be common among unbooked patients. ${ }^{2,16,20}$ The role of this alternative care for women during pregnancy and childbirth is not well specified in our health care system, yet they attend to about 60 $75 \%$ of parturient in these area. ${ }^{16}$

As reported by others in developing countries, ${ }^{2,9,10}$ most cases in this study resulted from neglected prolonged obstructed labour and commonly presented with total incontinence of urine. However, $13.5 \%$ of the fistulae followed abdominal operative delivery including caesarean operations and hysterectomy for uncontrolled primary postpartum haemorrhage. Also some patients were having repeat caesarean deliveries carried out by inexperienced surgeons in other institutions.

Table 4. Type and outcome of treatment in patients with fistula.

\begin{tabular}{|c|c|c|c|c|}
\hline Treatment & No. $(\%)$ & $\begin{array}{c}\text { Satisfactory } \\
\text { No. }(\%)\end{array}$ & $\begin{array}{l}\text { Unsatisfactory } \\
\text { No. }(\%)\end{array}$ & $\begin{array}{l}\text { Follow up } \\
\text { No. }(\%)\end{array}$ \\
\hline Conservative (bladder drainage) & $8(21.6)$ & $7(33.3)$ & $1(7.7)$ & - \\
\hline Bladder and vaginal repairs only & $6(16.2)$ & $2(9.5)$ & $3(23.1)$ & 1 \\
\hline $\begin{array}{l}\text { Ureteric excisions, repairs, } \\
\text { implantations }\end{array}$ & $4(10.8)$ & $4(19.1)$ & - & - \\
\hline Urethroplasty & $3(8.1)$ & $2(9.5)$ & - & 1 \\
\hline Others & $5(13.5)$ & $3(14.3)$ & $1(7.7)$ & 1 \\
\hline Referrals & $11(29.7)$ & 3 (14.) & $8(61.5)$ & - \\
\hline Total & $37(100)$ & $21(56.8)$ & $13(35.1)$ & $3(8.1)$ \\
\hline
\end{tabular}

Unlike reports from other developing countries, ${ }^{3,7}$ where average duration of symptoms was about 7 years, $48.7 \%$ of patients in our hospital reported for treatment within 6 months of delivery. This is not surprising as most of the patients were referred to this tertiary institution during labour and puerperium because of other complications. Also patients with long standing complications are usually poor, who may not afford the cost of a General Hospital treatment and would prefer to go to nearby Missionary Hospital where treatment are free or at minimal cost.

Vesicovaginal fistula was the commonest type followed by combined fistula and the complex type. Others have reported similar findings from developing countries., ${ }^{2,712,21}$ Two patients who had repeated caesarean sections developed uterovesical fistula and subsequently presented with menouria and infertility. Some of the patients in this study had complete destruction of the bladder neck and urethra following obstructed labour. Associated complications such as nerve injury, significant vaginal scarring and stenosis, were also encountered in a large number of patients. Others also experienced these in Northern Nigeria and other developing countries. . $^{8,98,20}$ Therefore, apart from attending to the urinary fistula, these associated problems were also treated for proper rehabilitation of the patients.

Most patients (21.6\%) in this study were managed conservatively or prophylactically with prolonged continuous bladder drainage with good results. This was particularly useful in patients whose labour and deliveries were managed in the hospital and those with small fistula of less than $1 \mathrm{~cm}$. The majority (29.7\%) were either referred to a nearby Missionary Hospital or absconded without treatment. Unlike the report from other centres, $2,6,9,14,21,22$ the results of bladder repairs were largely unsatisfactory. This was very disappointing considering the fact that most of these patients presented early for treatment. However, most of the bladder defects were large (average size of $4 \mathrm{~cm}$ ) and a complex type with significant scaring, which made access to the defect difficult. The management of this type of injuries requires advanced techniques and technology such as tissue grafting, insertion of devices, ${ }^{4,5,12,13}$ which were limited in our center. It is hoped that as the uro-gynecology unit in our institution is fully developed, equipped and staffed by highly skilled personnel most of these patients will achieve continence and the number of unsatisfactory care reduced thereby enhancing patients' confidence in the hospital.

As reported by others, ${ }^{3,12,13,23,24}$ the ureteric and urethral repairs were very successful. Very experienced urologists in this center usually performed these operation. ${ }^{24,26}$ Some of these patients were referred to the hospital after several attempts have failed to secure continence in other centres. Cases done included ureteric anastomosis, re-implantation of ureters, uretero-neocystostomy and urethroplesty. There was no case of urinary diversion performed, as no patient required this important procedure.

The study suffers the shortcoming of being hospital based and with small sample size. A prospective community based multi-center study is being planned to assess management outcome of complex and complicated obstetric fistulas.

This age long obstetric morbidity is still prevalent among underprivileged women who have socio-cultural and religious restrictions to access modern obstetric care in the $21^{\text {st }}$ century in Akwa Ibom State. The result of surgical management of the commonest type is poor due to lack of appropriate technology and the requisite expertise to handle them.

It is recommended that preventive strategies to obstructed labour such as comprehensive application of partogram in labour management. Well equipped Regional centers with trained personnel in urogynecology should be established in each zonal area in the country to take care of the complex fistulas and also retrain other health providers to acquire skill in repairing Waaldijk ${ }^{26,27}$ type I and II cases. Training of Traditional birth Attendants and other alternative obstetric caregivers by the government may be considered until such a time when enough trained midwives are available to take over from them. 
10. Waaldijk K, Armiya'u YD. The obstetric fistula: a major public health problem still unresolved. Int Urogynecol J 1993;4:126-8.

1. Harrison KA. Obstetric fistula: One social calamity too many. Br J Obstet Gynaecol. 1983;80:385-6.

2. Lawson JB. Management of genito-urinary fistulae. Clin Obstet Gynecol 1978;5:209-36

3. Thompson JD. Vesicovaginal and Urethrovaginal fistulas. In: J. Rock and J. Thompson (eds). Te-Linde's operative Gynecology. 8th edition. 1997 Lippincott, Raven Pub., Philadephia, PA, USA.

4. Goswami R, Wadhwa P, Sharma SKI. High bilateral ureteric injury during Caesarean Section birth and a unique repair. Int $\mathrm{J}$ Gynecol obstet. 2003;80:167-8.

5. Cruikshank SH. Early closure of post hysterectomy vesico-vaginal fistulas. South Med J 1988;81:1525-8.

6. Kelly J. Repair of obstetric fistulae. Review from an overseas perspective. The Obstetrician \& Gynaecologist 2002;4:20511.

7. Wall LL. Obstetric fistulas in Africa and developing world: new effort to solve an age-old problem. Womens Health Issues 1996;6:229-34.

8. Margolis T, Mercer IJ. Vesicovaginal fistula. Obstet Gynecol Surv 1994;49:840-7.

9. Attah CA, Ozumba BC. Management of unrepairable urinary fistulae in a developing country. ANZ J Surg 1993;63:217-20.
19. Ada-Ogar AM, Imo EK, Brennan M. The effect of training traditional birth attendants on maternal morbidity in area of Akwa Ibom State, Nigeria. Postgrad Doct Afr 1996;18:86-90.

20. Tahzib F. Vesicovaginal fistula in Nigerian Children. Lancet 1998;2:1291-3.

21 Hilton P, Ward A. Epidemiological and surgical aspects of urogential fistula: a

review of 25 years' experience in southeast Nigeria. Int Urogynecol J Pelvic Floor Dysfunct 1998;9:189-94.

22. Davits RJ, Miranda SI. Conservative treatment of vesicovaginal fistulas by bladder drainage alone. Br J Urol 1991;68:155-6.

23. Khanna S. Posterior bladder flap plasty repair of vesicourethrovaginal fistula. $\mathrm{J}$ Urol 1992;147:656-7.

24. Essiet A, Irekpita EE, Etuk SJ, Ekanem AD. Ureteric injuries complicating obstetric and gynecologic operations in the University of Calabar Teaching Hospital. Global J of Med Sci 2004;3:1-3.

25. Melah GS, Massa AA, Yahaya UR, Bukar M, Kizaya DD, El-Nafaty EU. Risk factors for Obstetric fistulae in North Eastern Nigeria. J Obstet Gynecol 2007;27:819-23.

26. Waaldijk K. The immediate management of fresh obstetric fistula. Am J Obstet Gynecol 2004;191:795-9.

27. Waaldijk K. Surgical classification of obstetric fistula. Int $\mathrm{J}$ Gynaecol Obstet 1995;49:161-3. 